\title{
The Transformative Potential of Emissions Trading
}

Originally published in:

Carbon Management, 6 (2015), 5-6, 261-272 DOI: $10.1080 / 17583004.2016 .1151552$ 
Lukas Hermwille $a$,

Wolfgang Obergassel a

Christof Arens a

\section{The Transformative Potential of Emissions Trading}

a Wuppertal Institute for Climate, Environment and Energy, Germany

* Corresponding author:

Lukas Hermwille

Wuppertal Institute

Research Group: Energy, Transport and Climate Policy

Döppersberg 19

42103 Wuppertal

Germany

E-mail: lukas.hermwille@wupperinst.org

Phone: +49 2022492284

This is the author's version of a work that was accepted for publication. Changes resulting from the publishing process, such as editing, corrections and structural formatting, may not be reflected in this document. Changes may have been made to this work since it was submitted for publication. A definitive version was subsequently published in the Journal cited above. 


\begin{abstract}
Limiting global warming below $2^{\circ} \mathrm{C}$ or even $1.5^{\circ} \mathrm{C}$ requires a fundamental transformation of global socio-economic systems. This need for transformation has been taken up by international climate policy. This article synthesis criteria of transformational change from transformation research and climate finance agencies. On this basis, the article conducts a multi-criteria evaluation of the transformative potential of the EU ETS, the world's currently largest market-based climate policy. From this case it can be inferred that emission trading can 'destabilise' incumbent highemission practices but their effectiveness in fostering innovation is limited. Furthermore, the analysis shows that details in the arrangements of the scheme such as allocation rules can have a strong detrimental impact on its outcome. If a global carbon market with a uniform price was introduced, this could lead to developing countries "buying in" with large amounts of freely allocated allowances. This, however, has been shown to thwart transformational effects and instead contribute to further carbon lock-in.
\end{abstract}

\title{
Key words
}

Emissions Trading; Market-based mechanisms; Sustainability Transformation; Carbon Pricing; ; Mitigation measures 


\section{Introduction}

The Paris Agreement to the United Nations Framework Convention on Climate Change (UNFCCC) has established the objective of holding "the increase in the global average temperature to well below $2{ }^{\circ} \mathrm{C}$ above pre-industrial levels and to pursue efforts to limit the temperature increase to $1.5^{\circ}$ C" (UNFCCC 2015, Paris Agreement Art. 2a). There is general agreement that maintaining this temperature limit requires a fundamental transformation of the global economy. For instance, the latest assessment report by the Intergovernmental Panel on Climate Change (IPCC) notes that "The stabilization of greenhouse gas concentrations at low levels requires a fundamental transformation of the energy supply system, including the long-term phase-out of unabated fossil fuel conversion technologies and their substitution by low-GHG alternatives" (IPCC 2014, 46). The German Advisory Council on Global Change (WBGU) similarly holds that preventing irreversible damages will require unprecedented international cooperation, new welfare concepts, technological leaps, manifold institutional innovations and adaptable reform alliances. The WBGU posits that there have so far been only two transformations of comparable magnitude in human history: the neolithical revolution, during which human societies became sedentary and started agriculture, and the industrial revolution (WBGU 2011).

This call for transformation has been taken up in international climate policy. The Green Climate Fund (GCF) has been given the mandate to promote a "paradigm shift towards low-emission and climate-resilient development pathways" (UNFCCC 2012, 58) and other international funding mechanisms such as the NAMA Facility - funded by the governments of Germany, the United Kingdom, Denmark and the European Commission - also demand that activities should contribute to "transformational change" (Green Climate Fund 2014; NAMA Facility 2014). But public finance, disbursed through the GCF or bilaterally, will not suffice to provide the means for implementation at the levels required to meet the extraordinary challenge ahead. Private funding will have to accompany these public funds in order to spur the necessary investments in lowemission infrastructures worldwide. Market-based mitigation instruments, and in particular emission trading, have been proposed by many to leverage such private sector engagement (IETA 2014; Marcu 2014; Edenhofer et al. 2013). Consequently, national and regional emission trading schemes have been established in many regions of the world and are planned in many others (ICAP 2015).

This article serves a dual purpose: It aims to flesh out more explicitly what the concept of transformative change should mean in the context of climate change mitigation, and it systematically analyses whether one of the most propagated mitigation instruments - emission trading - can 
deliver or at least contribute to the required transformation. The article develops a set of criteria and corresponding indicators to assess the transformative potential of mitigation instruments building on a succinct review of the relevant scientific literature on transitions/transformations and a synthesis of the funding criteria of various climate finance agencies that have explicitly stipulated to aim for transformative change (section "Assessing transformative change").

Subsequently, the article reviews existing literature in the light of these criteria and indicators in order to assess the case of the EU Emissions Trading Scheme (EU ETS). The insights generated from both the literature review and the case study will inform a general discussion of the transformative potential (company-based) emission trading, which will form the basis for the development of recommendations (section "Discussion").

\section{Methodology and material}

The analysis will be guided by a multi-criteria appraisal. The criteria will be developed in section "Assessment criteria" based on a review of the literature on socio-technical transformations/transitions and a synthesis of funding criteria for transformative change as applied in the climate finance domain.

A variety of climate finance institutions have expressed the ambition to focus their support on actions with transformational potential. Four of these institutions have made their ambition explicit:

- The Green Climate Fund has been given the mandate to promote a "paradigm shift" and has subsequently elaborated the criteria to determine the paradigm shift potential of proposed projects (Green Climate Fund 2014);

- The British-German NAMA Facility has defined a list of questions to assess the transformational potential of proposed projects (NAMA Facility 2014);

- The Climate and Development Knowledge Network (CDKN) has proposed assessment criteria in its policy brief "How can the Green Climate Fund initiate a paradigm shift?“" (Harmeling et al. 2013);

- The UK Department for International Development (DFID) through its International Climate Fund (ICF) is seeking to maximize its impact by bringing about transformational change, e.g. through facilitating institutional and policy change. DFID has developed key performance indicators that help to assess the transformative impact of its supported activities (DFID 2014). 
In the subsequent section the case of the EU ETS is analysed by reviewing the extensive literature on the impacts of the scheme in the context of the criteria and indicators developed below. The relevant literature has been identified through a strategic snowballing approach, starting out with articles providing a meta analysis of the impacts and effects of the EU ETS (Laing et al. 2014; Calel 2013; Branger et al. 2013; Venmans 2012; Wråke et al. 2012; Bailey 2010; Convery 2009; Clò 2009). In order to cover also the more specific aspects of our analysis, this was complemented with parameterized snowballing from three additional reference points: innovation (Borghesi et al. 2015; Schmidt et al. 2012; Kemp and Pontoglio 2011), investments (Jong, Couwenberg, and Woerdman 2014; Löfgren et al. 2013; Grubb 2012), institutions (Voß and Simons 2014; Hildén 2014; LaBelle 2012), and integration (Lehmann and Gawel 2013; Schlomann and Eichhammer 2014; Gawel, Strunz, and Lehmann 2014).

\section{Assessing transformative change}

\section{Characteristics of transformative change}

Studies of how transformative change, often also referred to as transitions, comes about have been a rapidly emerging field of research over the last decade. Transition studies conceptualise socio-technical systems according to the generic societal function they fulfil such as mobility, energy provision or food production. A socio-technical system is further defined as "a configuration of elements that include technology, policy, markets, consumer practices, infrastructure, cultural meaning and scientific knowledge" (Geels and Kemp 2012, 49).

A transition is a long-term and co-evolutionary process of change where all of these elements mutually influence each other, ultimately amounting to major shifts in the overall system configuration. As this process includes not only physical changes in infrastructures or organisations but also a redefinition of norms and values, new perspectives on how certain problems are framed and eventually acted upon, a transition can be defined as a substantial shift in the deep and underlying structure of a system. In successful transitions, the dynamics in different societal subsystems and the interactions between these subsystems are co-evolutionary processes which reinforce each other (Geels and Kemp 2012; Grin, Rotmans, and Schot 2010; Rotmans and Loorbach 2010; Shove and Walker 2007).

To grasp the dynamic processes by which these types of changes unfold, transition research has developed a multi-level perspective (MLP). The MLP conceptualizes transitions as a dynamic interplay of processes across three levels - landscape, regime, and niches - that interact and reinforce each other. These levels do not refer to specific spatial or organizational locations, but ra- 
ther to a more theoretical idea of virtual levels characterized by different degrees of structuration. Thus, a regime is understood as the deep structure that lies behind the stability and pathdependency of socio-technical systems, explaining their basic logic of functioning. The regime level "is the rule-set or grammar embedded in a complex of engineering practices, production process technologies, product characteristics, skills and procedures, ways of handling relevant artefacts and persons, ways of-defining problems; all of them embedded in institutions and infrastructure." (Rip and Kemp 1998, 338). Regime structures are shaped by an exogenous landscape that embodies the highest degree of structuration in so far as it cannot directly be influenced by individual groups of actors. The lowest degree of structuration can be found at the level of niches where new things are tried out that deviate from dominant regime logics (Geels 2011; Geels and Kemp 2012; Rotmans and Loorbach 2010).

Given the multi-dimensional nature of transformational processes, it follows that structural change processes and paradigm shifts cannot be completely planned and strictly steered. However, it is possible to support transformations by increasing factors for successful transformations, and, as a result, to help directing the system towards an intended development pathway.

Typically, every transformative process which a system undergoes can be depicted as a (stylised) S-curve with four phases "the pre-development phase where the status quo system dominates, but non-visible changes in the background take place; the take-off phase, where the process of structural changes is gaining momentum; the acceleration phase, where structural changes become visible and the stabilization phase, where a new regime is established" (Weseley et al. 2013, 44; Mersmann and Wehnert 2014).

In summary, transformations are not linear processes as result of intentional actions of powerful actors, but suites of interacting dynamics playing out on different timescales but congealing in one direction. General characteristics of transformation are (WBGU 2011):

- Large-scale change processes are co-evolutionary, that is, involving a multitude of changes in differing socio-technical (sub-)systems and take place at local, national and global levels.

- They include both the development of (niche) innovations as well as their selection by users and societal anchoring through markets, regulations, infrastructures and new societal norms.

- They are influenced by large numbers of actors from politics, science, business, civil society and individuals.

- They are ultimately radical processes regarding their impacts and reach, but may take decades to complete. 
Due to the scales of the required changes, an individual policy instrument can hardly be determined as transformative (Mersmann and Wehnert 2014). Generally, from today's state of knowledge it seems impossible to identify transformations ex ante let alone control them (Stirling 2014). Winkler and Dubash (2015) point out that the question of who defines transformation, which pathway to choose and which goal to aim at, remains unresolved.

To determine the transformative potential of policy instruments, it is therefore necessary to assess whether a proposed instrument opens up space for new and more sustainable sociotechnical configurations or whether it closes down incumbent unsustainable ones. Governing transformations cannot be successful as a top-down bureaucratically planned process. This is impeded by the inherent uncertainty that comes with the development of new and untested socio-technical configurations and the need to co-evolve at multiple levels and socio-technical subsystems (Smith, Stirling, and Berkhout 2005; Stirling 2014; Leach, Scoones, and Stirling 2010; Scoones, Leach, and Newell 2015).

Unsustainable socio-technical systems worldwide need to "become fundamentally different, not just higher cost versions of the same [...] systems." (Grubb, Hourcade, and Neuhoff 2014, 457). "Responses which help to adjust the long-run trajectory - through diverse possible mechanisms - may be much more valuable than just cutting emissions alone.” (ibid, 459). The criteria synthesised in the subsequent section need to be viewed and understood not as definitive, in the sense that a policy that ticks every box will lead to a transformation with certainty, but rather as yardsticks that help to determine whether or not a policy would or could constitute such a response in the context of a transformative portfolio.

Transition theory and in particular the MLP must not be mistaken for a grand theory of change. Instead, it has been devised as a middle-range theory and as such focuses on the dynamics of transitions in relatively limited socio-technical systems (Geels and Schot 2010). The unit of analysis, i.e. the socio-technical regime under consideration, is typically restricted within sectoral and/or national borders. Achieving transformative change at the scale of national sectorial level is precisely what has been the aim of many mitigation activities (NAMAs) by developing countries that seek international financial support. While it has been widespread practice by climate finance donors to fund more limited mitigation projects in the past, with the scale up of global mitigation activities it will be necessary to move this practice from individual projects to the level of sectoral programmes and/or policies. Climate finance institutions such as the GCF and the NAMA Facility have recognized this need and expressed their intentions accordingly. 
Table 1: Overview of assessment criteria for transformative change applied in the climate finance domain.

\begin{tabular}{|c|c|c|c|c|c|}
\hline Criteria & Indicators & 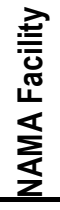 & 岁 & $\begin{array}{l}z \\
\text { 号 } \\
\end{array}$ & 음 \\
\hline \multirow{5}{*}{$\begin{array}{l}\text { Impact beyond } \\
\text { project scope }\end{array}$} & change of prevailing structures & $\mathrm{x}$ & & & \\
\hline & promotion of technology transfer & $\mathrm{x}$ & & & \\
\hline & technological learning & $\mathrm{x}$ & $\mathrm{x}$ & & $\mathrm{x}$ \\
\hline & economies of scale & & $\mathrm{x}$ & & $\mathrm{x}$ \\
\hline & sustainability co-benefits & $\mathrm{x}$ & $\mathrm{x}$ & $\mathrm{x}$ & \\
\hline \multirow{3}{*}{ Building capacities } & administrative capacities & $\mathrm{x}$ & $x$ & $\mathrm{x}$ & $\mathrm{x}$ \\
\hline & private sector sensitization & $\mathrm{x}$ & & & $\mathrm{x}$ \\
\hline & identification of sustainable business cases & & $\mathrm{x}$ & & $\mathrm{x}$ \\
\hline $\begin{array}{l}\text { Redirection of investment } \\
\text { flows }\end{array}$ & $\begin{array}{l}\text { shift of investment patterns towards sustainable } \\
\text { types of production and consumption }\end{array}$ & $\mathrm{x}$ & $\mathrm{x}$ & & $\mathrm{x}$ \\
\hline $\begin{array}{l}\text { Political and social integra- } \\
\text { tion }\end{array}$ & $\begin{array}{l}\text { integration with other policies into a coherent } \\
\text { policy mix }\end{array}$ & $\mathrm{x}$ & $\mathrm{x}$ & $\mathrm{x}$ & \\
\hline
\end{tabular}

\section{Transformative change in international climate finance}

The assessment criteria applied by the various funding institutions can be categorized into four main points: impact beyond the project scope, improving capacities, diversion of investment flows and integration into wider political and social debates. However, the assessment approaches differ in the emphasis they apply to these categories respectively. For a summary of the proposed criteria see table 1 above.

\section{Impact beyond the project scope}

A necessary condition for a mitigation instrument to be considered "transformative" is that it fulfils its prime objective, i.e. it reduces GHG emissions. However, this condition is not considered sufficient. For a truly transformative impact all funding institutions analysed in this paper consider more multidimensional impacts imperative. The NAMA Facility for example highlights a need to change prevailing structures, e.g. through tackling systematic barriers. Others highlight the need to promote the transfer of technologies between developed and developing countries and increased deployment of low-carbon technologies thus realising a decrease of technology costs through learning and economies of scale (NAMA Facility, GCF, DFID).

Interestingly, while a number of funders highlight the need for "innovative policies", the need for 'policies for innovation' is not taken up. Arguably, another desirable impact beyond the project scope would be that it spurs (private sector) investment in research and development resulting in innovation of technologies and practices that can have positive spill-over effects into other parts 
of the (global) economy. The transformative challenge is to steering the technological "best practice frontier" towards zero carbon sustainability (c.f. Grubb, Hourcade, and Neuhoff 2014).

Last but not least, more immediate co-benefits for wider sustainable development objectives, such as employment, health, local environmental benefits, are considered as an essential complement to the long-term transformative impact of a given instrument (GCF, NAMA Facility, CDKN).

The focus on a variety of impact dimensions beyond pure GHG mitigation reflects the coevolutionary nature of socio-technical transformations. Technological change alone will not result in the type of deep restructuration of large parts of societies and economies necessary on the way towards sustainable and climate compatible system.

\section{Building capacities: Strengthening learning and knowledge}

The built-up of capacities is highlighted by all institutions assessed above. This reflects a need to realign or in some cases create administrative institutions that are able to guide and govern a transition towards a more sustainable socio-technical system. Programs or instruments that contribute to a "strengthening of knowledge, collective learning processes, or institutions" (Green Climate Fund 2014, 9) are therefore to be prioritized.

But the need for improved capacities is not limited to administrative capacities. To foster transformation corresponding capacities are needed also in the private sector to optimize current business practices and to identify sustainable business models for the future.

Also the idea to support innovative programs and policies that are replicable elsewhere (GCF, NAMA Facility, DFID) reflects a notion of capacity building. Testing such innovative approaches will increase the global portfolio of policies, making it potentially easier to combine and select appropriate policy mixes for any given national circumstances.

The focus on such innovative approaches and the idea of investing in a portfolio of different approaches (DFID, GCF) resonates well with the concepts of transition management, in which deliberate experimentation with a wide set of promising approaches is a core element (Kemp, Loorbach, and Rotmans 2007; Weseley et al. 2013; Loorbach 2010).

\section{Redirection of investment flows}

A successful transformation to prevent dangerous climate change will require enormous investments in low-carbon technologies at all scales and across all sectors of the economy. Estimates of the additional investment needed globally to achieve the below $2^{\circ} \mathrm{C}$ target range from USD 260 
billion to 1.8 trillion annually (Sterk et al. 2014). A common criterion across all assessed approaches is therefore the question whether a particular instrument does alter investment patterns towards more sustainable types of production and consumption. The necessary shift of investment flows cannot be achieved through the realignment of public funds alone, it will also require the inclusion of the private sector (NAMA Facility).

A key objective of all assessed approaches is also the idea that lock-in of unsustainable technologies and/or infrastructures is to be avoided. Especially in the power sector, energy intensive industries, buildings and transport investments are typically extremely long-lived. Investments in technologies and infrastructures that appear to provide efficiency gains in the short term may prevent more fundamental change in the long run (Unruh 2000; Unruh 2002).

To avoid this, it is necessary to create an enabling environment for investments in low carbon technologies. In many cases this will mean changing the terms of "natural selection" in an evolutionary economics sense in favour of low-emission solutions. To assess the transformative potential of a mitigation instrument with regard to this criterion would mean to discuss whether or not the respective instrument can add to this enabling environment.

\section{Integration into wider political and social debates}

As noted above, one individual instrument cannot bring a transformation about on its own. Most funding institutions therefore require the supported instruments to be embedded in a larger policy package or strategy (NAMA Facility, GCF, CDKN). Again the idea of a portfolio of instruments comes to the fore.

The integration of a supported mitigation instrument is not only desirable to embrace the coevolutionary nature of transformative change, it typically also helps to increase the ownership of implementing countries. The required transformational change does not come about in an instant but over decades. To govern change processes over this time scale, any instrument will need to rely on a strong basis of support to be able to send (investment) signals credibly and tenaciously. In that sense mitigation instruments may prove to have a stronger transformative impact if they feature self-sustaining properties. Creating a complementing yet interdependent policy puzzle might thus increase the persistency of individual policies.

To be effective in driving transformative change towards sustainability, Kivimaa and Kern (2015) argue for a balanced policy mix with 'motors of creative destruction' - policies that aim to support innovation and creating niches to develop and mature sustainable solutions in combination with policies that challenge unsustainable practice and destabilise the incumbent socio-technical regime. 


\section{Case study: the EU Emissions Trading Scheme}

Flyvbjerg (2006) argues that it is possible to generalize from individual cases if they constitute 'critical cases" that have "strategic importance in relation to the general problem. [...] 'If it is not valid for this case, then it is not valid for any (or only few) cases." (Flyvbjerg 2006, 230-231). The EU ETS is such a critical case for a number of reasons. It was one of the very first GHG trading systems in the world, previously, there had only been limited systems in the UK and Denmark (Ellerman, Convery, and Perthuis 2010). It is by far the largest and most comprehensive market-based mitigation policy in the world. Not only was the EU ETS one of the first of its kind, it was also promoted as a prototype for a global carbon market system (Ellerman, Convery, and Perthuis 2010). There now is a distinguishable trend towards the development of new company-level cap-and-trade emissions trading schemes in many regions of the world (World Bank 2015). If the EU ETS does not contribute to transformational change (or only marginally so), then it is not very likely that other company-level ETS will do so.

In the remainder of this section we will explore the transformative potential of EU ETS. We will do so by looking beyond the instrument itself and instead look into wider effects in sociotechnical and socio-economic subsystems. The chapter is organized in accordance with the criteria spelled out above.

\section{Necessary condition: Reducing emissions}

First and foremost, the EU ETS has succeeded in achieving its prime objective: to reduce GHG emissions in the regulated sectors. Even accounting for the generous allocation of permits, the EU ETS drove emissions 2.5 to 5 per cent below business-as-usual emissions in the first trading period 2005-2007 (Venmans 2012; Laing et al. 2014). A positive contribution is generally acknowledged for the second trading period 2008-2012 as well. However, due to the heavy impact of the financial and economic crisis it is difficult to clearly and unequivocally attribute the drop in emissions to the ETS (Bel and Joseph 2015). Despite widespread concerns, carbon leakage, i.e. a migration of carbon intensive industries to evade the regulation, leading to increased emissions outside the regulated area, has hardly occurred (Venmans 2012). Altogether, it can be credibly assumed that the ETS has substantially contributed to reducing GHG emissions and thus does comply with the necessary condition to contribute to transformative change. But what has been the ETSs impact beyond this central objective? 


\section{Impact beyond project scope}

The central idea of carbon pricing is to internalise external costs of GHG emissions. If companies face direct costs for every ton of $\mathrm{CO}_{2}$ they emit, they will take these emissions into account in everyday decision making. Jong et al. (2014) have found evidence that this is not only the case for managers who are confronted with the cost of carbon emissions immediately, but also for investors on stock markets. By correlating allowance prices with companies' share prices they demonstrate that the EU ETS does 'bite', i.e. that investors are sensitive to carbon prices and the relative carbon intensity of a firm is viewed as a significant factor in determining a company's value. This is in fact a fundamental change in investor behaviour that can be considered a change of prevailing structures, at least to some extent.

The impact on innovation of low-carbon technologies and diffusion of such technologies has, however, remained below expectations. Kemp and Pontoglio (2011) have reviewed the relevant literature on technological innovation through environmental policy instruments. While scholars relying on theoretical models of incentives typically suggest that the ETS should invoke increased $\mathrm{R} \& \mathrm{D}$ on low-carbon technologies and hence increased innovation, the empirical literature by means of econometric studies, empirical case studies or surveys of firms finds little evidence that this is actually the case under the given designs. The record of current carbon pricing instruments is particularly poor when it comes to the effect on radical innovations that imply a break with current competencies and technologies. Furthermore, they find that the adoption of innovative technologies can be influenced both positively as well as negatively depending on the specific arrangement of the policy instrument.

The contribution of the EU ETS to drive down the cost of low-carbon technologies through economies of scale is also estimated to be relatively low. One of the inherent features of a market based instrument is that its steering effect is completely based on cost structures and its neutrality towards certain technologies. Companies are completely free in choosing the means of mitigating the emission (or offsetting them). Firms will therefore naturally focus on those options first that are already proven and available at low cost. More targeted policy instruments such as technology specific feed-in tariffs are likely to have contributed much more strongly to the cost digression of photovoltaic and wind power experienced in recent years (Kemp and Pontoglio 2011).

With respect to wider sustainability co-benefits relatively little research has been published. On employment effects only one relatively old study could be identified (Anger and Oberndorfer 2008), which did not find any significant impact of the EU ETS on employment in Germany in the first trading phase. With respect to local environmental and health benefits no empirical re- 
search could be identified. The evidence base on sustainability co-benefits is therefore not solid enough to come to a decisive conclusion.

\section{Building capacities}

In order to achieve a fundamental and ultimately transformative change towards low-emission socio-economic system, capacities are necessary both in administrations and the private sector. The EU ETS certainly has contributed to the development of such capacities.

The increased sensitivity for carbon emissions through pricing as discussed above is already an indicator of built-up of such capacities. The EU ETS has spurred the emergence of an ecosystem of specialized traders, information brokers, banks, consultants, etc. providing services to regulated industries from the outside. Some authors go as far as describing this eco-system as an "instrument constituency" as "powerful collective actors who strategically market their solutions, for example, by engaging with problem discourses, recruiting important supporters, or seeking to outcompete other instruments for a dominant position in the 'toolbox of policymaking"' (Voß and Simons 2014, 6).

LaBelle (2012) finds that the institutional set-up of the EU ETS is relatively strong as compared to other fields of environmental policy making (e.g. energy efficiency policy in the EU). He highlights that the EU ETS as an institution with strong sectoral mandate represents "a dynamic method of mitigating sectoral risk" (p. 401) through bringing together various "specialized stakeholders to work together to create effective solutions which mitigate risks of rolling-out new technologies" (p. 400). His initial verdict therefore is that the EU ETS and the institutional set-up around it is well-designed to spur the deployment of low-carbon technologies.

\section{Redirection of investment flows}

Ultimately, a low-emission global economy will need a fundamental restructuration of physical infrastructures. A transformative policy must therefore contribute to a redirection of public and private investments into low-emission assets and avoid lock-in of high-emission infrastructures (Unruh 2000).

The jury is still out with respect to the ETS's impact on investments in the regulated sectors. The reviewed literature suggests that the right investment incentives strongly depend on the detailed arrangements of the ETS: allocation plans (grandfathering, benchmarking or auctioning), closure rules for installations to be shut down at the end of their lifetime, and the provisions of the new entrants reserve. 
Theoretic economic models for a long time predicted that efficiency of emissions trading would be independent from the chosen allocation mode (Montgomery 1972). However, more recent (empirical) research has shown that this is not the case. Iterative grandfathering, i.e. the free allocation of allowances on the basis of historic emissions in every trading period, has been proven to be particularly unhelpful. It can be shown that this mode of allocation is particularly favourable for inefficient and highly polluting installations. If allocations are based on historic output or performance, companies have an incentive to artificially extent the lifetime of an old installation in order not to forgo the allocation of free permits that can be sold in subsequent trading periods (e.g. Neuhoff, Martinez, and Sato 2006; Ellerman 2008).

The flaws in the EU ETS allocation scheme became apparent during the first and second trading periods. Especially power producers drew in significant windfall profits as they were able to pass on opportunity costs of freely allocated allowances to end consumers. In response to this, the EU has revised its allocation mechanism. Allocation plans were centralised in the third trading period and the share of allowances to be auctioned substantially increased as free allocation to the power sector was completely abolished (Venmans 2012).

Despite these changes in the ETS design, there is little empirical evidence that the EU ETS has triggered substantial investments into low-carbon technologies. This is largely attributed to high price volatility in the market and overall low carbon prices. Both are a consequence of a high degree of uncertainty over the stringency of EU climate policy in general and the ETS in particular (Venmans 2012; Kirat and Ahamada 2011; Fontini and Pavan 2014; Bonenti et al. 2013; Jarait $\square$ and Di Maria 2012; Hoffmann 2007; Löfgren et al. 2013; Grubb, Hourcade, and Neuhoff 2014).

To conclude, the EU ETS has contributed less than expected to investment in low-carbon technologies. In part, this was due to allocation mechanisms that set the wrong incentives. However, the ETS has undergone reforms to adjust the incentive structure. A second reason for the suboptimal performance is over-allocation of permits which in combination with the unexpected effects of the European financial and economic crisis led to a substantial oversupply of allowances and hence low carbon prices; too low to incentivize long-term investments in low-carbon technologies. Mending both price levels and allocation mechanisms, the ETS's impact on investments could probably be greatly improved.

\section{Integration into wider political and social debates}

The EU ETS is part and parcel of the wider Integrated Energy and Climate Package of the EU. The EU's 20-20-20 in 2020 policy aims for a reduction of GHG emissions of 20 per cent as 
compared to 1990 levels, increase the share of renewable energy to 20 per cent, and to reduce primary energy consumption 20 per cent below business as usual. Within this package the ETS is specifically targeted to address the emission reduction, Various other instruments exist to support the deployment of renewable energy and increase energy efficiency both at the EU and at the member state level.

It has been argued that such an integration into a policy package is beneficial and necessary if the emission cap of the ETS is not negotiated independent from the regulated entities. A policy mix may also be necessary to accommodate multivalent policy goals such as nuclear phase out or renewable energy goals as a means of industrial policy (Gawel, Strunz, and Lehmann 2014; WBGU 2011; Löfgren et al. 2013).

The EU's integrated approach has been largely successful. Not only is the EU on track to meeting its emission reduction goal, it is also because of the interaction of the various integrated instruments that the EU's climate and energy policy did not collapse entirely in the face of the recent financial and economic crisis. Connie Hedegaard, former EU Climate Commissioner and as such responsible for the EU ETS, stated in October 2013 that "[d]uring the economic crisis we had more than one target and that has helped us a lot. Imagine if we had only had a $\mathrm{CO}_{2}$ target and the ETS during this crisis. Would Europe have continued to have such a strong focus on energy efficiency and renewables? I don’t believe it.” (quoted in Euractiv 2013).

Despite these successes, the integration of the ETS with other instruments has been under attack. Several mainstream economists continue to argue that the ETS should be sufficient to achieve the climate policy objectives and any other policy will negatively affect the ETS's efficiency in doing so. (e.g. Sinn 2011). There has been criticism that the price crash of the EU ETS has been partly due to the parallel implementation of policies to promote energy efficiency and renewables. However, the efficiency and renewable energy parts of the EU climate and energy package were taken into account when the ETS cap was set (Capros et al. 2008). The actual scale-up of renewables has so far been in line with the projections made during the preparation of the climate and energy package. The efficiency and renewables pillars of the climate and energy package can therefore not be blamed for the problems of the EU ETS (Hermann and Matthes 2012).

The future of the ETS as part of a wider policy package remains disputed. The debate over the upcoming $2030 \mathrm{EU}$ target was dominated to some extent by the question whether the EU should stick to the three complementary goals or whether it should only commit to one single GHG reduction target. While the European Parliament favoured three binding targets, parts of the European Commission in line with some member states and industry groups favoured a single target 
that would eventually be accompanied by non-binding renewables and efficiency targets (Euractiv 2014).

\section{The devil is in the detail}

Despite numerous deficits, there has been some transformative impact of the EU ETS. However, it is also clear that the transformative potential of the instrument has not fully been realized yet.

The analysis has shown that many of the EU ETS's sub-optimal performances can be attributed to flaws in the detailed arrangements of the scheme:

- Free allocation of permits creates perverse incentives and can lead to lock-in of out-dated, inefficient technologies.

- Closure rules and rules for new entrants can similarly lead to lock-in.

- High price volatility and overall low price levels fail to provide a long-term incentive for R\&D for low-carbon technologies.

- A high degree of uncertainty induced by the changing political economy prevented the ETS from providing a long-term signal for investments in low-carbon technologies.

Most of these flaws, however, can be redeemed through adjustment in the detailed arrangements of the ETS. For example, the lack of a long-term incentive for investment in low-carbon technologies and the high degree of uncertainty can (partially) be accounted for by price management, e. g. through minimum prices or price collars (Grubb 2012). In fact, most of the more recently established ETSs, the Californian ETS, the various Chinese pilot ETSs as well as the prospective Korean scheme, feature some form of price management mechanisms (ICAP 2015). Even in the EU the idea of a minimum price has been taken up by member states. The UK has introduced a flexible carbon tax to emulate a minimum price for the regulated entities under the EU ETS (Ares 2014).

Distortions through free allocations and new entrant and closure rules have already been tackled to some extent by the increased use of auctioning in the third trading period (Stenqvist and Åhman 2016), but may prove a bit more difficult to avoid altogether. Free allocation has been a tool to secure the support of wide ranges of industry in order to establish the ETS in the first place. And it has been argued that, in the absence of effective border adjustments, they remain important to accommodate concerns over carbon leakage for industries that are subject to international competition (Monjon and Quirion 2011). 


\section{Discussion}

WBGU (2011) argues that for the type of transformative change necessary to avoid (permanently) trespassing planetary boundaries it is inevitable to internalise the external effects of carbon pollution into economic decision making. They argue for carbon pricing as a central building block of the regulatory framework to avoid dangerous climate change. However, WBGU also states that carbon pricing alone is not sufficient to redeem the various types of market failures that have led to the current unsustainable global socio-economic system. Grubb, Hourcade and Neuhoff (2014) go even one step further and opine that a global carbon price is a "false god" and argue that it is critical to complement it with policies that more immediately direct user behaviour and that actively govern or even steer innovation and strategic infrastructure development.

The above assessment of the transformative potential of the EU ETS resonates well with this verdict: Market-based mitigation instruments can put a price on carbon, but this alone is not sufficient to induce the required change in unsustainable practices. Therefore, even if the flaws on the implementational level can be dealt with, the ETS will need to be integrated in a wider policy mix. It can be an effective instrument that puts economic pressure on current unsustainable practices, if prices are high and stable enough and free allocation of permits is repealed. As such the ETS can function as a 'motor of destabilisation' of unsustainable economic practices, but it fails to be a 'motor of innovation' (Kivimaa and Kern 2015). As a technology neutral policy it does not provide a protected space for emerging more sustainable technologies. The EU ETS's track record for spurring innovation is poor. More targeted policies are necessary to complement the ETS and make up for these deficiencies.

The EU and others promote the development of market-based mitigation instruments with a view to create global carbon market. While various design options exist and not all of them provide for a direct price incentive to the private sector (Wehnert, Arens, and Sterk 2012; Bolscher et al. 2012; Sterk et al. 2015), a new market mechanism under the UNFCCC is nevertheless seen as an intermediate step on the route to a unified global carbon market, facilitating the establishment of domestic emission trading systems in more and more countries.

This article has argued that the question of allocation rules is key for the determination of the transformative potential of emission trading. Yet, the promise to provide free allocations was key to gain industry support to agree on the EU ETS in the first place, as it is said to limit potential adverse effects on competitiveness of regulated versus non-regulated companies (Hepburn 2006; Egenhofer 2007). Others have argued that increased free allocation may shift political economies in a way that would allow to agree more stringent regulation overall (Hanoteau 2005, cited in 
Gawel, Strunz, and Lehmann 2014). In fact, it may well be the case that free allocation mechanisms are a 'necessary evil' to be able to establish an ETS.

However, emission trading can only unfold its potential to function as a 'motor of destabilisation' if this 'evil' is overcome quickly. The question is how fast this change in allocation practices can practically occur. The EU ETS changed its allocation mechanisms already after its second trading period and as a result the share of free allocation was strongly reduced. However, there still exist generous exemptions from the general auction of permits for heavy industries.

The EU ETS was established as a response to the EU's legal obligation to reduce GHG emissions under the Kyoto Protocol. For developing countries, to date there is no such obligation. Also in the Paris Agreement, where also developing countries have agreed to take on nationally determined contributions, the use of cooperative approaches including through the use of market-based instruments remains voluntary (UNFCCC 2015, Paris Agreement Art. 6; see also Obergassel et al. 2016). Under these circumstances, one has to ask critically how fast this change of allocation practices can be expected to occur in a developing country. If it is not possible to rule out large quantities of freely allocated allowances in the EU ETS, where the scheme itself is built on a legal obligation of the member states, it is deemed highly unlikely that developing countries will do without providing free permits to their industries quickly enough to spur transformative change, especially if their (sectoral) ETS was subject to international competition by directly linking it to international carbon markets.

In fact, the push to extend carbon markets to developing countries is driven to some extent by the idea that industrial production in developing countries, due to its environmental inefficiency, hosts a large mitigation potential available at relatively low-cost. For regulated entities in developed countries this would provide a means to meet their obligations more cost-effectively (see also UNFCCC 2012, para. 83). For developed country industries this would be very beneficial, but it would most likely not create a 'level playing field' for industrially competing industries. Given national and international differences in capacity to pay, a uniform carbon price is socially regressive. Treating dissimilar cases alike is as inequitable as treating similar cases differently (Verbruggen 2011; Sterk and Hermwille 2013; Grubb, Hourcade, and Neuhoff 2014).

Introducing emission trading in a developing country, exposing the newly regulated industry fully to carbon price levels that reflect the mitigation costs and more importantly capacities to pay of developed country competitors, would dramatically change the terms of business in the country. A company in the country with a newly established ETS would face competing bids from European companies who not only have a higher capacity to pay but also would need less allowances per unit of output because of their allegedly higher carbon efficiency. In addition, large-scale 
capital inflow from the sale of emission units would lead to foreign exchange appreciation of the selling countries' currency, further damaging its companies' competitiveness. Mattoo and Subramanian find that a plausible combination of carbon price increases and transfers from emission trading could result in a decline of India's manufacturing output by more than 5\% and a decline of manufacturing exports of more than 10\% (Mattoo and Subramanian 2013).

It is therefore highly unlikely that any developing country would voluntarily participate in such an instrument without being able to protect their industries and buffering the effect of carbon pricing via some amount of free allocations. While it may be possible to compensate developing countries at the national level for participating in a global carbon market, it seems very difficult to pass through this compensation to the private sector without compromising its transformative effectiveness.

\section{Conclusions}

Transition research generally holds that transformations are not linear processes as result of intentional actions of powerful actors, but cases of interacting dynamics playing out on different timescales but congealing in one direction. They are co-evolutionary, that is, involving a multitude of changes in differing socio-technical (sub-)systems and take place at local, national and global levels.

In order to unfold a transformative potential, (sectoral) policy instruments need not only to achieve a deviation from business as usual, it needs to shift what business as usual constitutes. A transformative policy instrument should have impact beyond its immediate scope, it should contribute to a build up of capacities in administration and the private sector, it should be embedded in and advance wider political and social debates, and it should lead to a diversion of investments into sustainable technologies.

While carbon pricing in general and emission trading in particular can play a key role in destabilising the incumbent socio-technical regime, in isolation it is not sufficient to redeem the various types of market failures that have led to the current unsustainable global socio-economic system. In addition, the case study of the EU ETS has shown that details in the arrangements of the scheme - take the allocation of permits as an example - can significantly influence the incentive structure of the instrument. Small changes in the design can make huge differences whether an instrument supports transformative change towards a sustainable socio-technical system or to the contrary contribute to locking in incumbent unsustainable technologies and practices even further. 
The case of the EU ETS indicates that the practical potential for transformative impact of emission trading may be limited especially if the idea is to integrate national carbon markets in a global carbon market. As long as strong differences in the level of development exist, large differences in the capacities to pay and carbon efficiencies of existing industrial infrastructures will prevail. Creating a globally uniform carbon price would not create a level playing field as it would put industries and the general population in developing countries at a severe disadvantage. A slow convergence of domestic carbon prices is probably needed to actually make linking of systems politically possible (Tuerk et al. 2009). Pushing for direct linking of ETSs could create an incentive for governments in developing countries to rely on free allocation of permits in order to protect domestic industries and thus create and maintain an incentive for lock-in of unsustainable technologies.

A way forward could be not to open emerging ETSs directly to international carbon markets but instead begin with establishing a protected carbon market with full auctioning of permits but price management in the form of e.g. a price collar (Grubb, 2012). This would allow to limit the impact on the competitiveness of the domestic industry and at the same time meet a key precondition for the effectiveness of carbon pricing: certainty about future prices. The level of ambition and both minimum and ceiling price could gradually be increased to the point where it reaches the level of international carbon markets and linking of markets can be achieved without strong effects on the terms of trade.

\section{Acknowledgments}

This article is based on earlier research carried out under the JIKO Project funded by the German Federal Ministry of Environment (Bundesministerium für Umwelt, Naturschuts, Bau und Reaktorsicherheit der Bundesrepublik Deutschland - BMUB). The authors would like to thank Christiane Beuermann and two anonymous reviewers for their constructive comments on earlier drafts of this article. 


\section{References}

Anger, Niels, and Ulrich Oberndorfer. 2008. 'Firm Performance and Employment in the EU Emissions Trading Scheme: An Empirical Assessment for Germany'. Energy Policy 36 (1): 12-22. doi:10.1016/j.enpol.2007.09.007.

Ares, Elena. 2014. 'Carbon Price Floor'. Document SN/SC/5927. London: House of Commons Library. http://www.parliament.uk/briefing-papers/sn05927.pdf.

Bailey, Ian. 2010. 'The EU Emissions Trading Scheme'. Wiley Interdisciplinary Reviews: Climate Change 1 (1): 144-53.

Bel, Germà, and Stephan Joseph. 2015. 'Emission Abatement: Untangling the Impacts of the EU ETS and the Economic Crisis'. Energy Economics 49 (May): 531-39. doi:10.1016/j.eneco.2015.03.014.

Bolscher, Hans, J. Laan, J. P. M. Sijm, S. J. A. Bakker, T. Mikunda, T. Wehnert, W. Sterk, J. Hoogzaad, Matthieu Wemaere, and T. J. Conway. 2012. 'Design Options for Sectoral Carbon Market Mechanisms and Their Implications for the EU ETS-Final Report'. Amsterdam: ECN. https://www.ecn.nl/publications/BS/2013/ECN-O--13-030.

Bonenti, Francesca, Giorgia Oggioni, Elisabetta Allevi, and Giacomo Marangoni. 2013. 'Evaluating the EU ETS Impacts on Profits, Investments and Prices of the Italian Electricity Market'. Energy Policy 59 (August): 242-56. doi:10.1016/j.enpol.2013.03.026.

Borghesi, Simone, Francesco Crespi, Alessio D'Amato, Massimiliano Mazzanti, and Francesco Silvestri. 2015. 'Carbon Abatement, Sector Heterogeneity and Policy Responses: Evidence on Induced Eco Innovations in the EU'. Environmental Science \& Policy 54 (December): 377-88. doi:10.1016/j.envsci.2015.05.021.

Branger, Frédéric, Oskar Lecuyer, Philippe Quirion, and others. 2013. 'The European Union Emissions Trading System: Should We Throw the Flagship out with the Bathwater'. WIREs Clim Change. Doi 10. https://hal-enpc.archives-ouvertes.fr/hal-00866408/document.

Calel, Raphael. 2013. 'Carbon Markets: A Historical Overview'. Wiley Interdisciplinary Reviews: Climate Change 4 (2): 107-19. doi:10.1002/wcc.208.

Capros, P, L Mantzos, V Papandreou, and N Tasios. 2008. 'Model-Based Analysis of the 2008 EU Policy Package on Climate Change and Renewables'. June. Athens: National Techical University of Athens.

Clò, Stefano. 2009. 'The Effectiveness of the EU Emissions Trading Scheme'. Climate Policy 9 (3): 227-41.

Convery, Frank J. 2009. 'Reflections-the Emerging Literature on Emissions Trading in Europe'. Review of Environmental Economics and Policy 3 (1): 121-37.

DFID. 2014. 'ICF KPI 15: Extent to Which ICF Intervention Is Likely to Have a Transformational Impact'. London: UK Government - Department for International Development.

Edenhofer, Ottmar, Christian Flachsland, Robert Stavins, and Robert Stowe. 2013. 'Identifying Options for a New International Climate Regime Arising from the Durban Platform for Enhanced Action'. Cambridge, MA.

Egenhofer, Christian. 2007. 'The Making of the EU Emissions Trading Scheme: Status, Prospects and Implications for Business'. European Management Journal 25 (6): 453-63. doi:10.1016/j.emj.2007.07.004.

Ellerman, A. Denny. 2008. 'New Entrant and Closure Provisions: How Do They Distort?' The Energy Journal, 63-76.

Ellerman, A. Denny, Frank J. Convery, and Christian de Perthuis. 2010. Pricing Carbon: The European Union Emissions Trading Scheme. Cambridge University Press.

Euractiv. 2013. 'Hedegaard: More 2030 Climate Targets Would Be "Wise"'. http://www.euractiv.com/energy/hedegaard-2030-climate-targets-w-news-530979.

2014. 'Parliament, Commission Set for Clash over 2030 Clean Energy Goals'. http://www.euractiv.com/energy/parliament-commission-set-clash-news-532682. 
Flyvbjerg, B. 2006. 'Five Misunderstandings About Case-Study Research'. Qualitative Inquiry 12 (2): 219-45. doi:10.1177/1077800405284363.

Fontini, Fulvio, and Giulia Pavan. 2014. 'The European Union Emission Trading System and Technological Change: The Case of the Italian Pulp and Paper Industry'. Energy Policy 68 (May): 603-7. doi:10.1016/j.enpol.2013.12.020.

Gawel, Erik, Sebastian Strunz, and Paul Lehmann. 2014. 'A Public Choice View on the Climate and Energy Policy Mix in the EU - How Do the Emissions Trading Scheme and Support for Renewable Energies Interact?' Energy Policy 64 (January): 175-82. doi:10.1016/j.enpol.2013.09.008.

Geels, Frank W. 2011. 'The Multi-Level Perspective on Sustainability Transitions: Responses to Seven Criticisms'. Environmental Innovation and Societal Transitions 1 (1): 24-40. doi:10.1016/j.eist.2011.02.002.

Geels, Frank W., and René Kemp. 2012. 'The Multi-Level Perspective as a New Perspective for Studying Socio-Technical Transitions'. In . na.

Geels, Frank W., and Johan Schot. 2010. 'The Dynamics of Transitions: A Socio-Technical Perspective'. In Transitions to Sustainable Development - New Directions in the Study of Long Term Transformative Change, edited by John Grin, Jan Rotmans, and Johan Schot, 11-104. New York: Routledge.

Green Climate Fund. 2014. 'Further Development of the Initial Investment Framework'. Document GCF/B.08/20. Bridgetown: Green Climate Fund.

Grin, John, Jan Rotmans, and Johan Schot. 2010. Transitions to Sustainable Development: New Directions in the Study of Long Term Transformative Change. New York, London: Taylor \& Francis.

Grubb, Michael. 2012. 'Strengthening the EU ETS - Creating a Stable Platform for EU Energy Sector Investment'. Climate Strategies.

Grubb, Michael, Jean-Charles Hourcade, and Karsten Neuhoff. 2014. Planetary Economics: Energy, Climate Change and the Three Domains of Sustainable Development. New. Routledge.

Harmeling, Sven, Linde Grießhaber, Raju Pandit Chhetri, and David Eckstein. 2013. 'How Can the Green Climate Fund Initiate a Paradigm Shift?' Policy Brief. London: CDKN. http://cdkn.org/wpcontent/uploads/2013/10/Policy-brief_GCF-paradigm-shift_LR1.pdf.

Hepburn, C. 2006. 'Regulation by Prices, Quantities, or Both: A Review of Instrument Choice'. Oxford Review of Economic Policy 22 (2): 226-47.

Hermann, Hauke, and Felix C Matthes. 2012. 'Strengthening the European Union Emissions Trading Scheme - Facts, Measures and Implications'. Berlin: Öko-Institut. http://www.greenpeace.de/fileadmin/gpd/user_upload/themen/klima/20120610-StudieEmissionshandel-englisch.pdf.

Hildén, Mikael. 2014. 'Evaluation, Assessment, and Policy Innovation: Exploring the Links in Relation to Emissions Trading'. Environmental Politics 23 (5): 839-59. doi:10.1080/09644016.2014.924199.

Hoffmann, Volker H. 2007. 'EU ETS and Investment Decisions: The Case of the German Electricity Industry'. European Management Journal 25 (6): 464-74. doi:10.1016/j.emj.2007.07.008.

ICAP. 2015. 'International Carbon Action Partnership’. https://icapcarbonaction.com/.

IETA. 2014. 'IETA's Response on the NMM - UNFCCC Submission'. Geneva: IETA - International Emissions Trading Association.

IPCC. 2014. 'Technical Summary'. In Climate Change 2014: Mitigation of Climate Change. Contribution of Working Group III to the Fifth Assessment Report of the Intergovernmental Panel on Climate Change. Cambridge: Cambridge University Press.

Jaraitè, Jūratè, and Corrado Di Maria. 2012. 'Efficiency, Productivity and Environmental Policy: A Case Study of Power Generation in the EU'. Energy Economics 34 (5): 1557-68. doi:10.1016/j.eneco.2011.11.017.

Jong, Thijs, Oscar Couwenberg, and Edwin Woerdman. 2014. 'Does EU Emissions Trading Bite? An Event Study'. Energy Policy 69 (June): 510-19. doi:10.1016/j.enpol.2014.03.007. 
Kemp, René, Derk Loorbach, and Jan Rotmans. 2007. 'Transition Management as a Model for Managing Processes of Co-Evolution towards Sustainable Development'. International Journal of Sustainable Development \& World Ecology 14 (1): 78-91. doi:10.1080/13504500709469709.

Kemp, René, and Serena Pontoglio. 2011. 'The Innovation Effects of Environmental Policy Instruments - A Typical Case of the Blind Men and the Elephant?' Ecological Economics 72 (December): 28-36. doi:10.1016/j.ecolecon.2011.09.014.

Kirat, Djamel, and Ibrahim Ahamada. 2011. 'The Impact of the European Union Emission Trading Scheme on the Electricity-Generation Sector'. Energy Economics 33 (5): 995-1003. doi:10.1016/j.eneco.2011.01.012.

Kivimaa, Paula, and Florian Kern. 2015. 'Creative Destruction or Mere Niche Creation? Innovation Policy Mixes for Sustainability Transitions'. SPRU Working Paper 2015-02. Brighton: SPRUScience and Technology Policy Research, University of Sussex.

LaBelle, Michael. 2012. 'Constructing Post-Carbon Institutions: Assessing EU Carbon Reduction Efforts through an Institutional Risk Governance Approach'. Energy Policy 40 (January): 390-403. doi:10.1016/j.enpol.2011.10.024.

Laing, Timothy, Misato Sato, Michael Grubb, and Claudia Comberti. 2014. 'The Effects and SideEffects of the EU Emissions Trading Scheme'. Wiley Interdisciplinary Reviews: Climate Change 5 (4): 509-19.

Leach, Melissa, lan Scoones, and Andy C Stirling. 2010. Dynamic Sustainabilities - Technology, Environment and Social Justice. Oxon, New York: Earthscan / Routledge.

Lehmann, Paul, and Erik Gawel. 2013. 'Why Should Support Schemes for Renewable Electricity Complement the EU Emissions Trading Scheme?' Energy Policy 52 (January): 597-607. doi:10.1016/j.enpol.2012.10.018.

Löfgren, Åsa, Markus Wråke, Tomas Hagberg, and Susanna Roth. 2013. 'Why the EU ETS Needs Reforming: An Empirical Analysis of the Impact on Company Investments'. Climate Policy, no. July (December): 1-22. doi:10.1080/14693062.2014.864800.

Loorbach, Derk Albert. 2010. 'Transition Management for Sustainable Development: A Prescriptive, Complexity-Based Governance Framework'. Governance 23 (1): 161-83. doi:10.1111/j.14680491.2009.01471.x.

Marcu, Andrei. 2014. 'The Role of Market Mechanisms in a Post-2020 Climate Change Agreement'. CEPS Special Report. Brussels: Centre for European Policy Studies (CEPS). http://www.ceps.eu/publications/role-market-mechanisms-post-2020-climate-change-agreement.

Mattoo, Aaditya, and Arvind Subramanian. 2013. Greenprint. A New Approach to Cooperation on Climate Change. Washington, D.C.: Center for Global Development.

Mersmann, Florian, and Timon Wehnert. 2014. 'Shifting Paradigms: Unpacking Transformation for Climate Action'. Berlin: Wuppertal Institute.

http://wupperinst.org/uploads/tx_wupperinst/Transform_Shifting_Paradigms.pdf.

Monjon, Stéphanie, and Philippe Quirion. 2011. 'Addressing Leakage in the EU ETS: Border Adjustment or Output-Based Allocation?' Ecological Economics, Special Section - Earth System Governance: Accountability and Legitimacy, 70 (11): 1957-71. doi:10.1016/j.ecolecon.2011.04.020.

Montgomery, W. David. 1972. 'Markets in Licenses and Efficient Pollution Control Programs'. Journal of Economic Theory 5 (3): 395-418.

NAMA Facility. 2014. 'General Information Document 07 April 2014'. Berlin / London: BMUB / DECC. http://nama-

facility.org/fileadmin/user_upload/pdf/NAMA_Facility_General_Information_Document_April2014.pdf.

Neuhoff, Karsten, Kim Keats Martinez, and Misato Sato. 2006. 'Allocation, Incentives and Distortions: The Impact of EU ETS Emissions Allowance Allocations to the Electricity Sector'. Climate Policy 6 (1): 73-91. doi:10.1080/14693062.2006.9685589.

Obergassel, Wolfgang, Christof Arens, Lukas Hermwille, Nicolas Kreibich, Florian Mersmann, Hermann E. Ott, and Hanna Wang-Helmreich. 2016. 'Phoenix from the Ashes - An Analysis of the Paris Agreement to the United Nations Framework Convention on Climate Change'. Wuppertal: Wuppertal Institute. http://wupperinst.org/uploads/tx_wupperinst/Paris_Results.pdf. 
Rip, Arie, and René Kemp. 1998. 'Technological Change'. In Human Choice and Climate Change: An International Assessment, edited by Steve Rayner and Elizabeth L Malone, 327-99. Columbus, $\mathrm{OH}$ : Batelle Press.

Rotmans, Jan, and Derk Albert Loorbach. 2010. 'Towards a Better Understanding or Transitions and Their Governance: A Systemic and Reflexive Approach'. In Transitions to Sustainable Development - New Directions in the Study of Long Term Transformative Change, edited by John Grin, Jan Rotmans, and Johan Schot, 105-222. New York: Routledge.

Schlomann, Barbara, and Wolfgang Eichhammer. 2014. 'Interaction between Climate, Emissions Trading and Energy Efficiency Targets'. Energy \& Environment 25 (3-4): 709-32.

Schmidt, Tobias S., Malte Schneider, Karoline S. Rogge, Martin J.a. Schuetz, and Volker H. Hoffmann. 2012. 'The Effects of Climate Policy on the Rate and Direction of Innovation: A Survey of the EU ETS and the Electricity Sector'. Environmental Innovation and Societal Transitions 2 (March): 23-48. doi:10.1016/j.eist.2011.12.002.

Scoones, Ian, Melissa Leach, and Peter Newell, eds. 2015. The Politics of Green Transformations. Pathways to Sustainability. Oxon, New York: Routledge.

Shove, E, and G Walker. 2007. 'CAUTION! Transitions Ahead: Politics, Practice, and Sustainable Transition Management'. Environment and Planning A 4 (39): 763-70.

Sinn, Hans-Werner. 2011. The Green Paradox: A Supply-Side Approach to Global Warming. Cambridge, MA: MIT University Press.

Smith, Adrian, Andy C Stirling, and Frans Berkhout. 2005. 'The Governance of Sustainable SocioTechnical Transitions'. Research Policy 34 (10): 1491-1510. doi:10.1016/j.respol.2005.07.005.

Stenqvist, Christian, and Max Åhman. 2016. 'Free Allocation in the 3rd EU ETS Period: Assessing Two Manufacturing Sectors'. Climate Policy 16 (2): 125-44. doi:10.1080/14693062.2014.979130.

Sterk, Wolfgang, Hans Bolscher, Jeroen van der Laan, Jelmer Hoogzaad, and Jos Sijm. 2015. 'Developing a Sectoral New Market Mechanism: Insights from Theoretical Analysis and Country Showcases'. Climate Policy 15 (4): 417-37. doi:10.1080/14693062.2014.937384.

Sterk, Wolfgang, and Lukas Hermwille. 2013. 'Does the Climate Regime Need New Types of Mitigation Commitments?' Carbon and Climate Law Review 7 (4): 270-82.

Sterk, Wolfgang, Florian Mersmann, Hanna Wang-Helmreich, Timon Wehnert, Carsten Warnecke, Hanna Fekete, Thomas Day, and Cathrine Sachweh. 2014. Analysis of the Role Carbon Markets Can Play for Global Climate Finance from Today to 2020 and Beyond. Final Report. Wuppertal/Köln: Wuppertal Institute for Climate, Environment, Energy / Ecofys. http://www.carbonmechanisms.de/en/2015/what-role-can-carbon-markets-play-for-climate-finance/.

Stirling, Andy C. 2014. 'Emancipating Transformations: From Controlling "the Transition” to Culturing Plural Radical Progress'. http://steps-centre.org/wp-content/uploads/Transformations.pdf.

Tuerk, Andreas, Michael Mehling, Christian Flachsland, and Wolfgang Sterk. 2009. 'Linking Carbon Markets: Concepts, Case Studies and Pathways'. Climate Policy 9 (4): 341-57. doi:10.3763/cpol.2009.0621.

UNFCCC. 2012. 'Decision 2/CP.17 - Outcome of the Work of the Ad Hoc Working Group on LongTerm Cooperative Action under the Convention'. Document FCCC/CP/2011/9/Add.1. UNFCCC.

2015. 'Decision -/CP.21, Adoption of the Paris Agreement, Advance Unedited Version'. FCCC/CP/2015/L.9/Rev.1. Paris: United Nations Convention on Climate Change (UNFCCC). http://unfccc.int/resource/docs/2015/cop21/eng/l09r01.pdf.

Unruh, Gregory C. 2000. 'Understanding Carbon Lock-In’. Energy Policy 28 (12): 817-30.

2002. 'Escaping Carbon Lock-In'. Energy Policy 30 (4): 317-25.

Venmans, Frank. 2012. 'A Literature-Based Multi-Criteria Evaluation of the EU ETS'. Renewable and Sustainable Energy Reviews 16 (8): 5493-5510. doi:10.1016/j.rser.2012.05.036.

Verbruggen, Aviel. 2011. 'A Turbo Drive for the Global Reduction of Energy-Related CO2 Emissions'. Sustainability 3: 632-48. doi:10.3390/su3040632. 
Voß, Jan-Peter, and Arno Simons. 2014. 'Instrument Constituencies and the Supply Side of Policy Innovation: The Social Life of Emissions Trading'. Environmental Politics, no. July (June): 1-20. doi:10.1080/09644016.2014.923625.

WBGU. 2011. World in Transition - A Social Contract for Sustainability. Berlin: German Advisory Council on Global Change. http://www.wbgu.de/en/flagship-reports/fr-2011-a-social-contract/.

Wehnert, Timon, Christof Arens, and Wolfgang Sterk. 2012. 'Promoting Sustainable Development in New Market Mechanisms - Options and Limitations'. Wuppertal/Berlin: Wuppertal Institute for Climate, Environment and Energy. http://www.jikobmu.de/basisinformationen/publikationen/doc/1259.php.

Weseley, Julia, Georg Feiner, Ines Omann, and Niko Schäpke. 2013. 'Transition Management as an Approach to Deal with Climate Change'. In Proceedings of Transformation in a Changing Climate, 19-21 June 2013, edited by University of Oslo. Oslo: University of Oslo.

Winkler, Harald, and Navroz K. Dubash. 2015. 'Who Determines Transformational Change in Development and Climate Finance?' Climate Policy, April, 1-9. doi:10.1080/14693062.2015.1033674.

World Bank. 2015. 'State and Trends of Carbon Pricing 2015'. Washington DC: The World Bank. http://www-

wds.worldbank.org/external/default/WDSContentServer/WDSP/IB/2015/09/21/090224b0830f0f31/2 _0/Rendered/PDF/State0andOtrends0of0carbon0pricing02015.pdf.

Wråke, Markus, Dallas Burtraw, Åsa Löfgren, and Lars Zetterberg. 2012. 'What Have We Learnt from the European Union's Emissions Trading System?' Ambio 41 (1): 12-22. 